\title{
Talent Cultivation Mode on Accountancy and Bilingual Teaching Reform of Accounting Education
}

\author{
Dan-qing PAN
}

Guangdong University of Foreign Studies, South China of Business College, Guangzhou, China

Keywords: Application oriented college, Accounting in English, TED speech video, Practice teaching.

Abstract. China released its $13^{\text {th }}$ five-plan on education to deepen reform and promote the modernization of education, which is pursuit of transforming China from "Made in China" to "Created in China". The application oriented colleges play the significant role in implementing the objective. This template explains and demonstrates how to use TED to involve in bilingual teaching on Accounting Education and to increase the opportunity of practice teaching. There could be the solution to various theoretical and practical problems on talent cultivation mode on Accountancy and bilingual teaching reform of Accounting Education.

\section{会计人才培养和会计双语教学理论创新与发展}

\author{
潘丹青 \\ 广东外语外贸大学南国商学院, 广州, 中国
}

关键词: 应用型人才培养目标的本科院校; 会计英语; TED演讲视频; 实践教学

摘要： “十三五” 规划推进教育现代化、提升全民教育水平为题, 用 “教育水平明显提升” 作为目标，应用型人才培养目标的本科院校是实施该目标的主体之一，为完成新目标和新任 务必须创新工作举措。会计教育理念创新与发展, 结合双语教学和实践教学的推进落实, 能 够促进目前应用型本科会计教育存在的诸多理论与实践问题的解决。

“发展是第一要务, 人才是第一资源, 创新是第一动力。”2018年全国两会习主席在参加 广东代表团审议时提出经济要强起来靠创新, 创新则靠人才, 本土人才和海归人才要并用并 重。重视教学理念创新、培养应用型人才, 已引起国内外高教界普遍关注和重视。2010年《国 家中长期教育改革和发展规划纲要（2010-2020年）》印发后, 再一次引发高教界对应用型本 科院校的人才培养方案的探讨, 对办学模式和人才培养模式方面提出了很多改革的设想, 力 求改变应用型本科院校多年来那种教育与经济脱节、理论与实践脱节、千校一面、万人同语 的教学状况。学生逐渐意识到当代用人单位对毕业应届毕业生在职场沟通、问题处理分析能 力、专业技能和团队合作方面的迫切需求，同时应具备积极融入社会生活的意识。改变传统 的教学理念, 加大实践教学和双语教学, 不是简单的“拿来主义”, 创新应用型人才可以助力 把“中国制造”变成“中国创造”。事实已表明实践教学是培养学生实践能力和创新能力的重要 环节, 也是提高学生社会职业素养和就业竞争力的重要途径。双语教学是及时学习和掌握国 外先进的教学模式和课程体系的重要手段, 也是提高教师和学生对文化素养和国际交流能力 的必要行径, 培养创新人才的重要阶段。

会计英语是一门应用型极强的学科, 如何在会计双语教学过程中培养学生的职业能力与 职业素养, 是会计英语教学中的一道难题。会计英语教学不仅要向学生全面系统地用英语讲 授会计理论知识和基本方法, 且更要注意培养学生应用会计英语解决会计实践问题的能力。 
会计双语教学是指将母语外的另一种外国语言直接应用于非语言类专业课程教学, 并使外语 与学科知识同步获取的一种教学模式。通过会计双语教学, 旨在形成与国际先进教学理念与 教学方法接轨的, 对应用型人才培养目标的本科院校具有一定示范性和借鉴意义, 为培养学 生的国际竞争意识和能力发挥重要作用, 充分体现办学特色和优势的专业。

目前我国本科高校的会计英语教学方法却难以与学生的兴趣有效契合, 教学方法的设计 和应用仍停留在以教师为中心的灌输式教学模式, 即一本教材、一套标准答案的教学模式。 教学目标低、涉及内容窄, 应用层次低, 难以引起学生的兴趣, 学生感觉会认为会计英语的 教学与自己将来的就业或升学没有太大的关系, 从而影响了学生的实践能力和分析问题解决 问题能力培养，无法满足现代社会对应用型本科层次会计人才的要求。

本文是基于应用型人才培养目标的要求, 从理论与实践的结合上, 对应用型本科会计英 语实践教学模式的研究, 力图构建一个综合的会计双语教学体系, 对目前应用型人才培养目 标的本科院校会计教育存在的一些理论与实践问题的矛盾提供一定的参考意见, 对于其他专 业的专业英语建设也可提供一定的学术参考价值。

在会计双语教学体系上设计如何以学生能力提升为核心，构建一个既满足不同个体的差 异化实践需求, 又满足会计专业相关岗位之间、相关课程之间相互衔接教学的需求, 尽可能 达到学生的知识结构、能力结构和素质结构的培养目标需要, 有以下几点建议:

\section{1. 构建多维的实践教学模式}

在实践教学体系的设计上可以将会计英语实践教学划分为两个层次, 即角色扮演（或情 景模拟）和案例分析, 以及引入有四大外资会计事务所和外企财务工作经验的职场人士经验 分享交流会。

在实践教学内容的设计上要实现实践教学与理论教学的有机结合, 尽可能选取社会中一 些真实企业案例进行学习和交流, 仿效美国哈佛大学的case-based teaching, 案例都是来自于商 业管理中的真实情境或事件, 透过此种方式, 有助于培养和发展学生主动参与课堂讨论的积 极性。案例本质上是提出一种教育的两难情境, 而教师于教学中扮演着设计者和激励者的角 色, 鼓励学生积极参与讨论。在案例教学中, 没人会告诉你应该怎么办, 而是要自己去思考、 去创造, 使得枯燥乏味变得生动活泼, 而且案例教学的成果阶段, 每位学生都要就自己和组 员的方案发表见解。通过这种经验的交流. 一是可取长补短、促进人际交流能力的提高, 二 也是起到一种激励的效果, 引导学生变注重知识为注重能力。现在的公司管理者都知道知识 不等于能力, 知识应该转化为能力。而且让学生通过制作视频Video的过程, 把案例分析后想 要表达的结论和观点, 通过视频的方式在课堂上展示。第一, 可以激发学生的学习新鲜感, 在制作Video的过程中, 要对情景进行模拟, 练习口语; 第二, 在Video的制作过程中, 要进 行后期制作，字幕的完善是对专业英语写作最好的练习。

引入职场人士的交流会, 特别是四大会计师事务所及外企财务工作人士经验分享，会使 学生切身体会到会计英语教学紧跟社会工作实际需要, 从而增强对会计英语学习的兴趣。交 流会结合双语教学的要求, 尽量使用全英的演讲。所以, 在分享会进行前, 要对学生的专业 英语听力有一定的培训。学生除了在课后作业和期末考试使用专业术语完成外, 并没有其他 机会或者花大量业余时间去提高专业英语的听力和口语表述能力。同时缺乏了日常的语境和 氛围, 这令到学生很难提高专业英语的批判性思维和创新思维能力。随着互联网和网络公开 课 (MOOC) 的加快发展, 互联网的教学资源为教师和学生搭建起了一个无国界教育的一个 桥梁。TED演讲视频在中国的教育界于2009年开始受到大范围的重视。将TED演讲视频融入 传统课堂中, 通过在会计英语课堂上观看 TED 演讲视频, 不单纯为了18分钟的英文演说, 而 是一种很好的获取灵感、开拓思路、培养多元思考能力的好办法, 同时训练他们的听力和演 讲能力, 能够让学生在轻松的模式下掌握更多的词汇, 对于参加外企人士经验分享会来说是 相得益彰。 


\subsection{TED演讲视频能够在轻松的环境下令学生掌握更多的词汇和语法}

TED演讲视频根据演讲者的话题进行了细致的分类，并为其组织翻译多种语言字幕共享、 演讲词原文和多国语言的原文翻译。这是一个很好的教学资源平台。教师在会计双语课堂上 课前 10 分钟有所选择的为学生播放TED演讲视频, 并要求学生在看视频过程中对高级词汇的 关注作笔记。通过课堂上的第一次观看, 对所涉及的话题有所了解后, 在课后的时间对同一 个talk show 的内容进行无字幕多次观看, 然后用自己的语言和一些刚认识的高级词汇和语法 组织该话题的主要内容, 下一节课程中在同学们面前进行复述演讲。

这种方法在今天互联网信息时代中，是一个很好的立体化教学示范。利用TED演讲视频 的教学资源平台, 教师作为资源的引导者, 学生打破教学的时空限制, 将课堂教学与课外学 习联系起来, 师生间的互动不再局限在课堂。而且学生通过无字幕的观看TED演讲视频, 在 训练专业英语听力的同时, 还能训练笔录的技巧。这样的词汇记忆, 配合有情景的真实故事, 能够大大提升同学们使用词汇的频率和准确性。更重要的是对TED talk show的复述演讲, 能 够有效地训练同学们的口头表达能力和现场演讲的技巧。对于词汇的正确发音, 教师会从中 进行指导和纠正。而且现场演讲技能是当代大学生必须掌握的一个基本技能, 在日后的工作 中是展示工作成果的必要工具。同学们在轻松的环境中掌握大量的高级词汇, 对于会计双语 课程的理解及其专业外文文献的阅读发挥及其重要的作用。

\subsection{TED演讲视频可以激发学生的创新思维能力}

TED演讲视频规定演讲者必须在18分钟以内阐述自己的观点或者讲述自己的故事。因此 演讲者为了这18分钟能够更好地展现自己往往会花上数周或者数月的时间来精心准备。有机 会来到 TED现场的演讲者都有着非同寻常的经历, 他们要么是某一领域的佼佼者, 要么是某 一新兴领域的开创人, 要么是做出了某些足以给社会带来改观的创举。由于演讲者对于自己 所从事的事业有一种深深的热爱, 他们的演讲也往往最能打动人心, 并引起大家的思考和进 一步的思索。

学生创新能力的培养一直是国内外教育界关注的重点。把TED演讲视频应用于会计双语 的课堂中, 是为了在学生中推进“群体加速创新”。通过让学生观看、思考、概括、复述这些 演讲, 激发学生了解、开发陌生领域的兴趣和创造灵感, 赋予他们全球化、多远化的视角。 看 TED 演讲不是单纯为了18分钟的英文演说, 而且是一种很好的获取灵感、开拓思路、培养 多元思考能力的好办法。比起语言更重要的是, 需要让学生通过学习的过程, 拥有比现实生 活高一个层次看问题的视角, 这正是能够从 TED 演讲视频中学到的东西。对于学生来说, 每 两周选取观看一个TED talk show, 可以激发学生的创新意识和反思精神, 提高学生的听说能 力, 并可通过分析演讲内容, 帮助学生提高英语阅读理解能力。同时, 一个TED 演讲, 相当 于阅读一本人物传记。人格形塑是教育中的不可或缺的一部分。如同心理学家马丁. 赛林格曼 所说的, 幸福的最高境界是“使用你的长处，投身于超出个人的事业。”

\subsection{TED社团增加不同高校之间学术交流的机会}

当东西方文化因为地理位置产生隔阂的时候, 互联网的教学资源为学生搭建起了这个桥 梁。它也让学生和教师可以重新思考地理位置的意义。高等学校的教学定位是培养学生成为 国际化需要的人才。TED 演讲视频在教学中的应用能够使课程实施课内外教学结合、师生多 维互动的立体化教学模式成为可能。教师可以根据会计英语的内容从TED 演讲视频中衍生开 发其他相关的课程, 例如创业管理、公司理财等, 补充学生全方位的知识体系; 学生也可以 在课外组织TED 演讲俱乐部, 定期观看讨论并模仿TED 大会组织模式组织专业演讲俱乐部, 使专业英语学习不再局限在课堂, 提高学生的学习能力和自学意识。而且不同高校之间的TED 社团可以设定主题进行交流切磋, 让来自全国各地的学生们拥有一个广阔的学术交流平台。 


\section{2. 建立会计英语实践教学与理论教学有机结合的完整教学体系}

会计英语的实践教学模式研究就是要解决如何将会计英语实践过程融入整体的会计教学 体系中, 把实践教学与理论教学作为一个整体; 把各个实践教学模块作为一个系统工程, 把 对实践教学的投入看作对教学的重点投入一样重视并设定每个实践教学环节的评估指标; 校 企协同育人，通过“引企入校、引校入企”等，拓展校企合作育人的途径与方式，推动校企共 建校内外生产性实训基地, 推动专业人才培养方案与产业岗位人才需求标准相衔接, 人才培 养链和产业链相融合。

因此, 对实践教学的理念、教学计划、教学大纲、教学任务、教学目标、教学组织、教 学实施和设备、教学常规管理、教学质量监控等实践教学涉及的全部内容、要素、环节进行 全方位的研究, 形成体系化的方案和研究报告。结合学分制和人才培养目标, 全面修改《会 计英语》教学大纲、重新修订教材。以TED作为外语培训平台, 设置专题案例讨论库的共享 资源。

借鉴2013年北京市会计专业群建设项目、中央财经大学“211工程”重点学科建设项目和北 京工商大学教学改革项目 (JG125101和JG125206) 中提出我国高等院校递进的会计人才培养 目标应当在及时反映社会需求的基础上, 提炼出为社会需要的会计专业人才应需要的基本能 力和素养, 并在会计学位教育的不同层次形成逐步递进的会计人才培养目标。围绕专业知识 的构建、认知和智力技能、核心和转换能力、实务操作能力四个层次分解会计人才培养目标 （如表1所示）：

表1 高等院校递进的会计人才培养目标

\begin{tabular}{|c|c|c|c|c|c|}
\hline \multicolumn{2}{|l|}{ 项目 } & 级 ${ }^{\text {本科1-2年 }}$ & $\begin{array}{l}\text { 本科1-3年 } \\
\text { 级 }\end{array}$ & 硕士 & 博士 \\
\hline \multirow{3}{*}{$\begin{array}{c}\text { 专业知 } \\
\text { 识的构建 }\end{array}$} & 基础知识 & $\begin{array}{c}\text { 文理交叉 } \\
\text { 课程 }\end{array}$ & $\begin{array}{l}\text { 文理交叉课 } \\
\text { 程+专业课程 }\end{array}$ & $\begin{array}{l}\text { 系统的专 } \\
\text { 业课程 }\end{array}$ & $\begin{array}{l}\text { 系统而深厚的专 } \\
\text { 业课程+高质量论 } \\
\text { 文 }\end{array}$ \\
\hline & 理论道德 & 具备意识 & 形成道德观 & 运用 & 运用并解决冲突 \\
\hline & 方法论 & 无 & 初步掌握 & $\begin{array}{l}\text { 掌握并运 } \\
\text { 用 }\end{array}$ & 运用并创新方法 \\
\hline \multirow{4}{*}{$\begin{array}{l}\text { 认知和 } \\
\text { 智力技能 }\end{array}$} & 分析能力 & $\begin{array}{l}\text { 重点培养 } \\
\text { 批判性分析能 } \\
\text { 力 }\end{array}$ & $\begin{array}{l}\text { 重点培养批 } \\
\text { 判性分析能力 }\end{array}$ & $\begin{array}{l}\text { 运用批判 } \\
\text { 性分析能 } \\
\text { 力 }\end{array}$ & $\begin{array}{l}\text { 运用批判性分析 } \\
\text { 并创新 }\end{array}$ \\
\hline & 综合能力 & $\begin{array}{l}\text { 学会归纳 } \\
\text { 总结相关资料 } \\
\text { 和信息 }\end{array}$ & $\begin{array}{l}\text { 运用归纳总 } \\
\text { 结 梳理观点 }\end{array}$ & $\begin{array}{l}\text { 运用归纳 } \\
\text { 总结 提 } \\
\text { 炼观点 }\end{array}$ & $\begin{array}{l}\text { 运用归纳总结 } \\
\text { 抽象概念并创新 } \\
\text { 观点 }\end{array}$ \\
\hline & 评价能力 & 重点培养 & 强化 & 运用 & 运用 \\
\hline & 运用能力 & 重点培养 & 强化 & 运用 & 运用 \\
\hline \multirow{7}{*}{$\begin{array}{l}\text { 核心和 } \\
\text { 转换能力 }\end{array}$} & 才队合作 & 重点培养 & 强化 & 运用 & 运用 \\
\hline & 学习能力 & 重点培养 & 强化 & 运用 & 运用 \\
\hline & $\begin{array}{l}\text { 自我评价 } \\
\text { 能力 }\end{array}$ & 重点培养 & 强化 & 运用 & 运用 \\
\hline & $\begin{array}{l}\text { 管理信息 } \\
\text { 能力 }\end{array}$ & 重点培养 & 强化 & 运用 & 运用 \\
\hline & 自主能力 & 重点培养 & 强化 & 运用 & 运用 \\
\hline & 沟通能力 & 重点培养 & 强化 & 运用 & 运用 \\
\hline & $\begin{array}{l}\text { 解决问题 } \\
\text { 能力 } \\
\end{array}$ & 重点培养 & 强化 & 运用 & 运用 \\
\hline \multirow{3}{*}{$\begin{array}{l}\text { 实务操 } \\
\text { 作能力 }\end{array}$} & 运用能力 & 重点培养 & 强化 & 运用 & 运用 \\
\hline & 自主技巧 & 初步 & 一定 & 强化 & 强化 \\
\hline & 专业特长 & 无 & 无 & 无 & 强化 \\
\hline
\end{tabular}




\section{3. 提高教师教学水平}

师资队伍质量的高低往往决定着培养学生质量的优劣,对于会计学专业来说,实践教学的 师资队伍尤为重要。优化应用型人才培养目标的本科院校会计学专业实践教学的师资队伍应 该从以下几个方面入手:第一, 进一步提高专任教师队伍中实践教学教师的比例。随着专任实 践教学教师数量的递增, 其教学任务就会有所减轻, 教学质量就有保证。第二, 通过各种途径扩 大“双师型”教师比例,优化专任教师内部结构。双语教师队伍都拥有海外留学背景, 在实际教 学中使用国外当代较为流行的教材讲授西方先进的专业理论, 让学生在掌握国内会计学理论 的同时了解国外会计学科发展的基本情况。第三，加大对专任实践教学教师的培训,提高他们 的实践能力。给专业英语老师提供更多外国培训或出国进修的机会, 并鼓励老师们在教学之 余利用寒暑假进入外企、涉外机构等进行实践和学习, 获取更丰富的实践经验和专业知识, 在教学中能够充分发挥教师的主导作用。在“十三五”时期我国教育的新思路, 加强职业教育 双师型教务建设, 促进职业学校教师和企业技术人才双向交流。深入推进高校教师考核评价 制度改革，落实好支持教师和科研人员创业创新的相关政策，加大对青年教师的关心支持， 使他们安于从教、乐于从研。

2018年全国两会政府工作报告提到“发展公平而有质量的教育”，强调高质量发展，人才 是关键。未来广东现代产业体系的建立, 要提高自己的创新能力, 最终依靠的都是人才。这 不仅要求相关人员具备必要的职业素养, 还需要有相当的专业水平。会计的人才培养方案应 适应资本市场发展, 为创新发展服务, 为实体经济服务。结合粤港澳大湾区建设发展的机遇, 会计双语教学改革能促使本土专业人才更好地与海归人才和世界不同领域的人才更好地沟通 和进行深层次的合作。

\section{致谢}

本文系2013年广东省“质量工程”建设项目（粤教高函113号）会计学“专业综合改革试点” 项目阶段性成果和2014年广东省教育研究院教育研究课题“基于应用型人才培养目标的会计 英语教育模式创新研究（立项编号：GDJY-2014-D-b033）结题报告。

\section{References}

[1] Elaine H. J. Yew, Janice J. Y. Yong. Student perceptions of facilitators' social congruence, use of expertise and cognitive congruence in problem-based learning, [J]. Instructional Science .5(2014) 123-125

[2] Wei.Wu, The study on teaching method of Accounting in English, [J] .Economic Vision.4 (2013)45-46

[3] Jingjie.Lu, The application of TED in College English, [J] .College Journal of Changsha. 3 (2013) $10-12$.

[4] Trevor Stanley, Stephen Marsden. Problem-based learning: Does accounting education need it? [J] .Journal of Accounting Education. 2012(3-4)

[5] Marie H. Kavanagh, LyndalDrennan. What skills and attributes does an accounting graduate need? Evidence from student perceptions and employer expectations [J]. Accounting \& Finance 2008 (2) 